
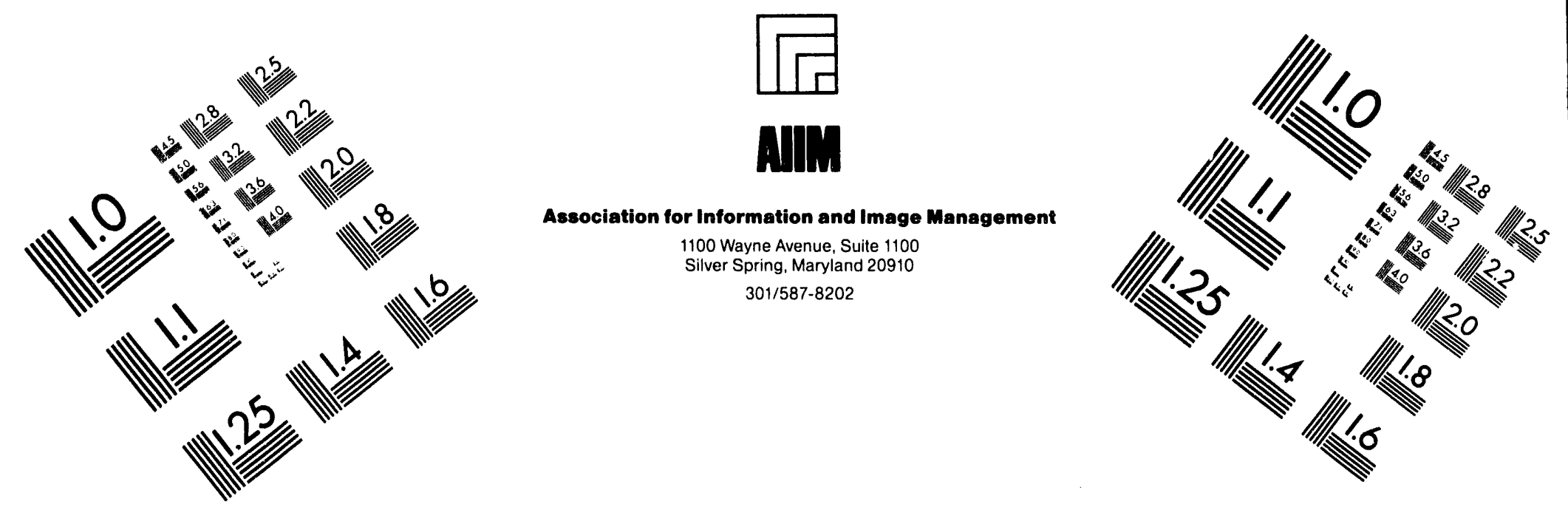

Centimeter

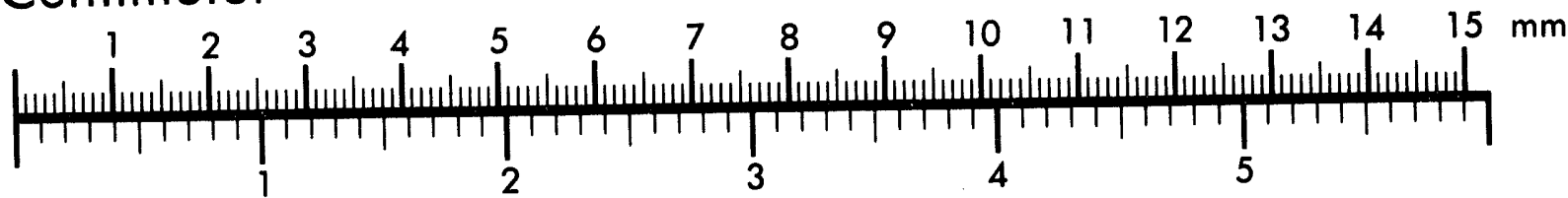
Inches
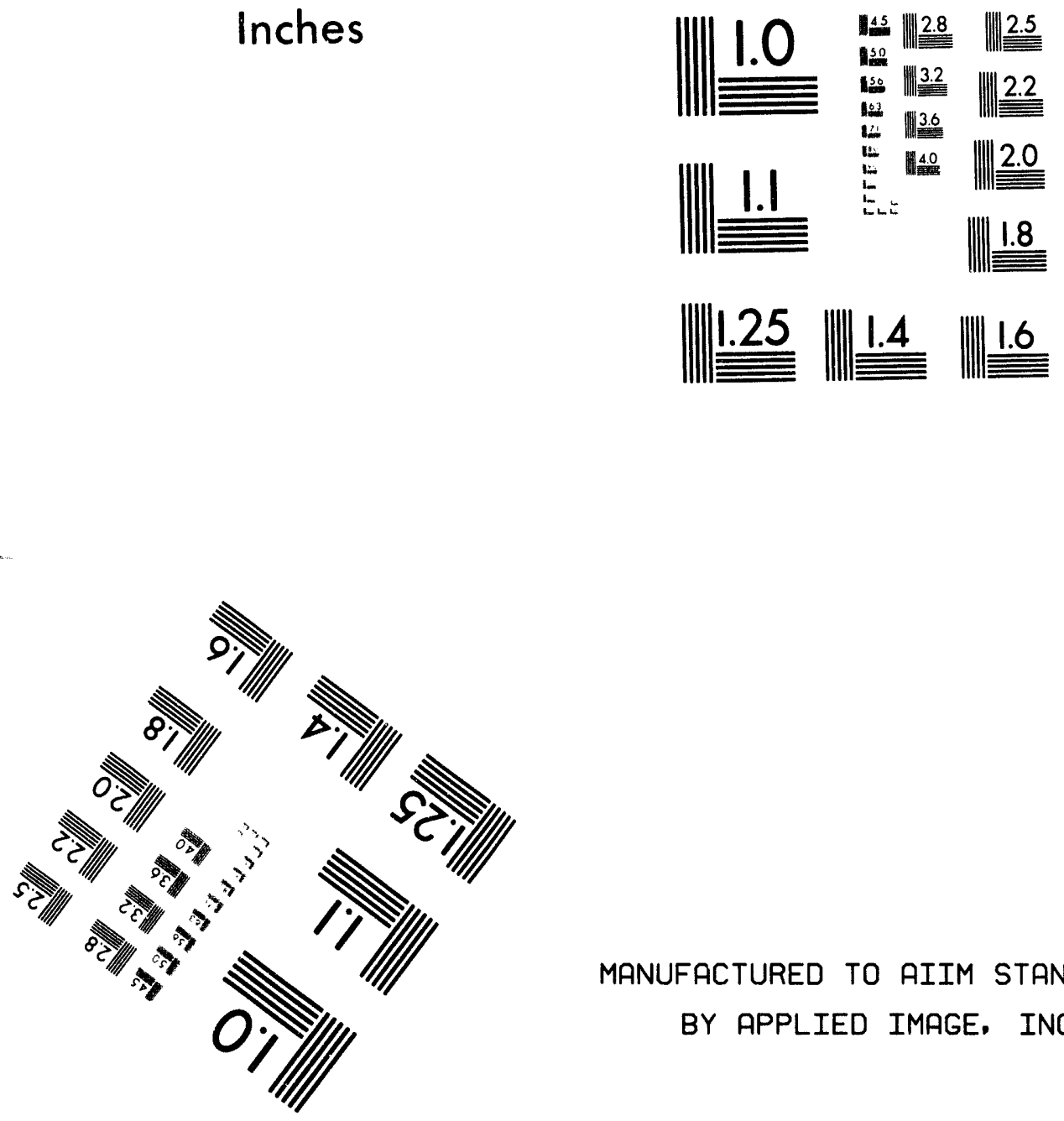

MANUFACTURED TO AIIM STANDARDS BY APPLIED IMAGE, INC.

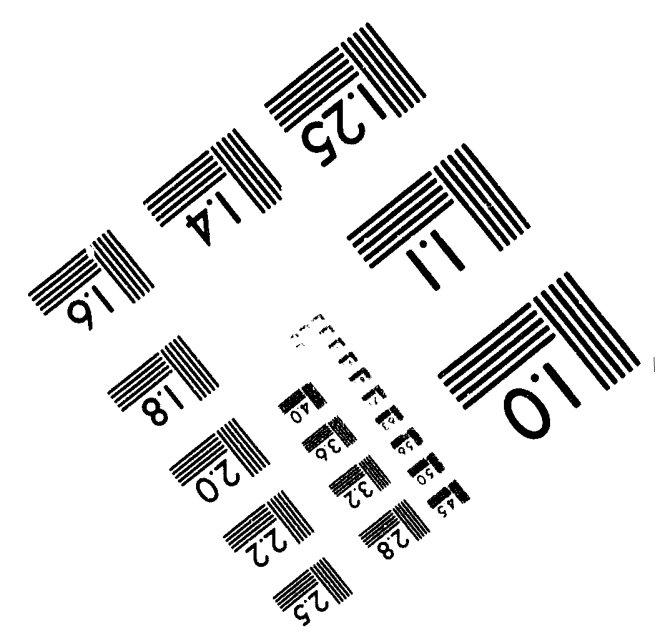



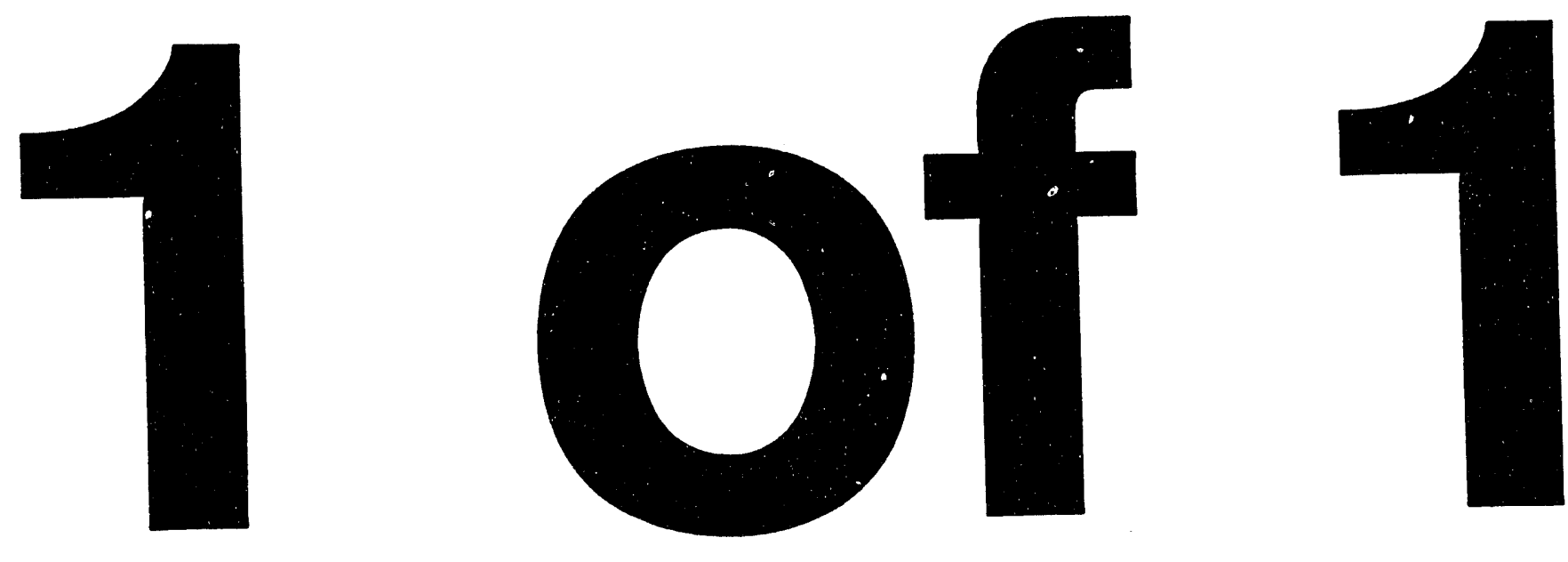
DOE/ER/13591-8

\section{POLYMER-BASED SEPARATIONS: \\ SYNTHESIS AND APPLICATION OF POLYMERS \\ FOR IONIC AND MOLECULAR RECOGNITION}

Annual Performance Report

August 1, 1993 - July 31, 1994

Spiro D. Alexandratos

University of Tennessee

Knoxville, Tennessee 37996

April 1994

\section{PREPARED FOR THE U.S. DEPARTMENT OF ENERGY \\ UNDER GRANT NUMBER DE-FG05-86ER13591 \\ DISTRIBUTION OF THIS DOCUMENT IS UNLMITED \\ yr}

DISCLAIMER

\begin{abstract}
This report was prepared as an account of work sponsored by an agency of the United States Government. Neither the United States Government nor any agency thereof, nor any of their employees, makes any warranty, express or implied, or assumes any legal liability or responsibility for the accuracy, completeness, or usefulness of any information, apparatus, product, or process disclosed, or represents that its use would not infringe privately owned rights. Reference herein to any specific commercial product, process, or service by trade name, trademark, manufacturer, or otherwise does not necessarily constitute or imply its endorsement, recommendation, or favoring by the United States Government or any agency thereof. The views and opinions of authors expressed herein do not necessarily state or reflect those of the United States Government or any agency thereof.
\end{abstract}


ALEXANDRATOS // 13591-8

Progress Report: August 1, 1993 - July 31, 1994

The current period has focused on the design and synthesis of bifunctional polymers for the selective complexation of metal ions from aqueous solutions. Such studies are within the Department's mission by providing for an efficient means of separating radioactive and otherwise toxic metal ions from contaminated waste water as well as valuable metals from dilute ore processing streams."

The modification of polymers by covalent bonding of ligands to a support matrix has been recognized as an important technique for the preparation of ion-selective polymers. In the most cases, a single type of ligand is bonded to the polymer and its selectivity for different metal ions then determined. Our approach has been to bond two different types of ligands on a polymer and then define the conditions under which the ligands cooperate in complexing greater levels of metal ions than either could complex when acting alone. In one example, polystyrene beads with phosphonate monoester and diester ligands complexed far more $\mathrm{Ag}(\mathrm{l})$ than expected from results with the corresponding monofunctional resins.

The synthesis of bifunctional polymers to study the synergistic interaction of supported ligands required a new preparative technique due to the limited number of reactions that could immobilize well-defined pairs of ligands on polymers. The development of bifunctional interpenetrating polymer networks (IPNs) was an

\footnotetext{
"Appropriate review of the literature may be found in the papers given in the Publication List. The following papers cited refer only to our publications for the current period.
} 


\section{ALEXANDRATOS // 13591-8}

important part of our studies during the current period. ${ }^{1}$ The sequential method of bifunctional IPN synthesis involves starting with a pre-formed crosslinked polymer, contacting it with a solution of monomers chosen on the basis of how their ligands can be expected to interact with metal ions, and polymerizing the second network within the first. In the IPN's synthesized to date, polystyrene beads form the first matrix into which the second network with ion exchange and coordinating ligands is immobilized. Carboxylic acid ligands allow for metal ion exchange and imidazole ligands allow for a selective coordinative interaction; they are incorporated into the polystyrene network by copolymerizing ethyl acrylate and $\mathrm{N}$-vinylimidazole monomers sorbed into the matrix. A subsequent deesterification yields the acid sites. Initial results show that the bifunctional IPNs offer a different binding environment to metal ions than the monofunctional analogues: as the imidazole:acid ligand ratio changes along the series $1: 0,0.5: 0.5$, and $0: 1$, binding constants for $\mathrm{Cu}(\mathrm{II})$ at $\mathrm{pH} 5$ are 3130 , 1556 , and $77 \mathrm{~N}^{-1}$, while for $\mathrm{Co}(\mathrm{II})$ are 294,189 , and $26 \mathrm{~N}^{-1}$, respectively.

The effect of the microenvironment surrounding the imidazole ligand on its ability to complex metal ions was probed with a series of po!y $(\mathrm{N}$-vinylimidazole-coethyl acrylate) IPNs, with imidazole being replaced by increasing levels of weakly coordinating carboxylate ester moieties. ${ }^{2}$ The strength of the imidazole--ion interaction is indeed sensitive to the polymer microenvironment: as the imidazole:ester ratio decreases along the series $1: 0,0.77: 0.23,0.53: 0.47,0.27: 0.73$, and $0: 1$, the $\mathrm{Cu}(\mathrm{II})$ binding constants from $\mathrm{pH} 5$ solutions are $3130,4134,8203,3108$, and $\mathrm{O} \mathrm{N}^{-1}$, 
ALEXANDRATOS // 13591-8

respectively, while the Co(II) binding constants are $294,270,86,129$, and $O \mathrm{~N}^{-1}$, respectively. The results suggest that the microenvironmental effect can be used to improve separations among different ions: under the given conditions, $\mathrm{Cu}(\mathrm{II})$ is held 10 times more strongly than Co(II) by the imidazole IPN and almost 100 times more strongly in the equimolar imidazole:ester IPN.

Solid state ${ }^{13} \mathrm{C}$ NMR spectroscopy was introduced as a technique which could refine our structural understanding of bifunctional IPNs. ${ }^{3}$ Network differences in the crosslink level and swelling characteristics allow DP/MAS (magic angle spinning) and CP/MAS to be used as complementary techniques for identifying both networks: DP/MAS gives the chemical composition of the lightly crosslinked network (in this case, polystyrene) under conditions where the more heavily crosslinked network (in this case, poly( $\mathrm{N}$-vinylimidazole-co-ethyl acrylate) $)$ is transparent; the latter is identified by CP/MAS. Combining the spectra with wet chemical analyses allows for an unambiguous determination of the ligands and their microenvironment. Ligand accessibility and completeness of reaction are also identified by the NMR: spectra of acrylate-containing IPNs which have been hydrolyzed with $\mathrm{KOH}$ indicate that cleavage of all ester sites occurs with no apparent degradation of the network.

Having shown in earlier research that polymers with two different types of ligands covalently bound to a single support can cooperate synergistically in the complexation of metal ions, it was decided to examine whether synergism can be found in a monofunctional polymer which has sorbed a mobile liquid extractant. This 
ALEXANDRATOS // 13591-8

novel type of solvent-impregnated resin represents a hybrid of solvent extraction and resin-based systems and offers new possibilities for developing improved separation systems. In collaboration with the ORNL Separations Group, a new extractive resin was prepared with the macrocyclic tetrathia-14-crown-4 (TT14C4) sorbed within polystyrene beads modified with sulfonic acid ligands. ${ }^{4}$ Following uptake of several weight percent TT14C4, the sulfonic acid resin exhibits a 10-100 fold enhancement in the cation exchange extraction of $\mathrm{Cu}(\mathrm{II})$ as quantified by its distribution coefficient. Since extraction of copper by unfunctionalized polystyrene beads is negligible, the enhanced complexation is attributed to a synergistic effect of $\mathrm{Cu}(\mathrm{II})$ coordination by the mobile macrocycle and cation exchange by the immobile sulfonic acid groups. This is the first demonstration of synergism in a solvent-impregnated resin involving a functionalized support.

Whereas most studies in the literature quantify metal ion selectivities under equilibrium conditions, it is important to note that industrial utilization of ion-selective polymers depends to a large extent on their kinetic performance: if high distribution coefficients are not achieved rapidiy, then the polymer cannot be applied to separations on the large scale due to the long contact times which would be required. It has now been shown that introducing sulfonic acid groups into polymers on which phosphonic acid ligands have been immobilized allows for a coupling of ionic selectivity with rapid rates of complexation. ${ }^{5}$ The two types of functional groups are introduced onto the polystyrene matrix by an Arbusov reaction followed by 


\section{ALEXANDRATOS // 13591-8}

sulfonation. In one example, polystyrene beads crosslinked with divinylbenzene and functionalized with phosphonic acid ligands alone, complex $5 \%$ of the Eu(III) present in a $1 \mathrm{~N} \mathrm{HNO}_{3}$ solution at a 30 min contact time; under the same conditions, a bifunctional phosphonic/sulfonic acid polymer complexes $51 \%$ Eu(III). The selectivity is retained and the results are comparable when a large excess of sodium ions is present. It was thus concluded that maximum metal ion complexation rates depend on a balance between chemical interactions (i.e., a bifunctional network interacting with a metal ion) and physical parameters (i.e., matrix porosity and rigidity). Structural integrity must be maintained through an appropriate crosslink level in order for the advantage of bifunctionality to be maintained in highly acidic solutions.

The fundamental study of bifunctional polymers has led to the commercial production of a novel ion exchange resin. A series of papers defining its properties has been published during the current period. ${ }^{6-12}$ The resin displays both ionic selectivity (due to the presence of diphosphonic acid ligands) and rapid rates of complexation (due to the presence of sulfonic acid ligands). Thus, the resin (Diphonix ${ }^{T M}$ ) complexes $96.5 \%$ Eu(III) present in a solution of $1 \mathrm{~N} \mathrm{HNO}_{3} / 0.4 \mathrm{~N} \mathrm{NaNO}_{3}$ after a 30 min contact time. Under identical conditions, a commercially available sulfonic acid resin complexes $14.3 \%$ Eu(III). In another example, Diphonix ${ }^{T M}$ has a $\mathrm{Zn}(I I)$ distribution coefficient of 130,000 while a sulfonic acid resin has a value of 0.67 and an iminodiacetic acid resin has a value of 17 . Diphonix ${ }^{T M}$ has been found to be superior to other resins in complexing actinide ions from very acidic solutions. 


\section{ALEXANDRATOS // 13591-8}

\section{Research Plan: August 1,1994-July 31,1995}

The budget period scheduled to begin August 1, 1994 will target four areas for research.

(i) Bifunctionality as a means of increasing complexation kinetics. Widespread application of ion exchange resins to environmentally important problems requires that polymers display both selectivity and rapid rates of complexation. Phosphorus acid polymers, in general, are much more selective relative to the commercially available sulfonic acid ion exchange resins for heavy metal ions. Phosphinate polymers, in particular, are selective for transition metal ions which can be reduced to the free metal $(\mathrm{Hg}(\mathrm{II}), \mathrm{Ag}(\mathrm{I})$, and $\mathrm{Cu}(\mathrm{III})$ through the ligand's $\mathrm{P}-\mathrm{H}$ bond, as well as for lanthanide/actinide ions in highly acidic solutions through coordination with the phosphoryl oxygen. Metal ion accessibility into the gel polymer matrix is, however, limited since complexation can require over six hours in order to reach equilibrium. In order to enhance the applicability of phosphinate polymers to metal ion separations, the variables which would be expected to result in rapid complexation rates will be studied. The variables include the resin particle size, matrix rigidity as determined by the percent crosslinking and the type of crosslinking agent, and macroporosity. The effect of making the polymer bifunctional by introducing sulfonic acid groups into the gel phosphonic acid resin will also be examined.

(ii) Microenvironmental vs. electronic effects in polymer-metal ion interactions. Differences in the complexing abilities of a given ion-binding ligand immobilized on 


\section{ALEXANDRATOS // 13591-8}

different polymer networks have been observed. It is important to define a general method whereby such differences can be assigned to a microenvironmental and/or an electronic effect. This would allow for changes in the microenvironment to be designed into the polymer support in order to enhance selectivity for a targeted metal ion. The experimental design to be studied includes the following points: (a) immobilize a given ligand onto various polymer supports le.g., phosphinic acid on polystyrene and other copolymers); (b) quantify the ion-binding abilities of the polymer-supported ligands with a target ion (e.g., Eu(III) in $1 \mathrm{~N} \mathrm{HNO}_{3}$ ); (c) record the solid state NMR of the polymers, focusing on nuclei (e.g., $\left.{ }^{31} \mathrm{P}\right)$ comprising the ligands. Conclusions will be drawn based on whether differences in the distribution coefficients are coupled with different or identical chemical shifts in relevant nuclei. At this point, it seems probable that the former case will correspond to an electronic effect on the distribution coefficients and the latter case will correspond to a microenvironmental effect on those values.

(iii) Solid state NMR as a means of characterizing bifunctional polymers. As part of an on-going effort in the synthesis of bifunctional polymers, a series of resins known as dual mechanism bifunctional polymers (DMBPs) has been developed. These polymers contain two different ligands which function in a cooperative manner to yield a higher level of complexation than can be attain ad from either ligand acting alone. Cooperativity is the key factor in the performance of these resins and an understanding of the interactions which exist between the different ligands is 


\section{ALEXANDRATOS // 13591-8}

important to designing polymers with selective ion-binding abilities. In the previous budget period, solid state ${ }^{13} \mathrm{C}$ NMR spectroscopy was successfully used to characterize bifunctional interpenetrating polymer networks. The current period will focus on the use of solid state ${ }^{31}$ P NMR to characterize DMBPs containing phosphorus ligands. Spectroscopic evidence of interactions between ligands will be sought as will the effect of the synthesis conditions on the uniformity of that interaction.

(iv) Polymer-supported catalysts. We propose to initiate a new area of research during the current period: the design and development of efficient catalysts for organic reactions. The catalysts will utilize acidic ligands and, hence, will involve polymers which can also be used as ion exchange resins. The initial focus will be on the Prins reaction which leads to the manufacture of many organic compounds via the condensation of olefins (from petroleum) with aldehydes. The reaction is catalyzed by sulfuric acid. We will study the sulfonic acid resin and the influence of the copolymer matrix on the reaction rate. Thus, the influence of the microenvironmental effect will be studied within the context of polymer-supported catalysts, as it also is within the context of selective metal ion complexation reactions. 
ALEXANDRATOS // 13591-8

PUBLICATIONS: AUGUST 1, 1993 - JULY 31, 1994

1. S.D. Alexandratos, C.E. Grady, D.W. Crick and R. Beauvais Bifunctional Interpenetrating Polymer Networks Advances in Chemistry Series, No. 239; "Interpenetrating Polymer Networks"; ACS Books; American Chemican Society: Washington, DC 1994. Chapter 8.

2. S.D. Alexandratos, C.G. Ciaccio and R. Beauvais The Microenvironmental Effect in lon-Complexing Interpenetrating Networks Reactive Polymers 19, 137-143 (1993).

3. D.W. Crick and S.D. Alexandratos Characterization of Bifunctional Interpenetrating Polymer Networks via SolidState ${ }^{13} \mathrm{C}$ NMR Spectroscopy Macromolecules 26, 3267-3270 (1993).

4. B.A. Moyer, G.N. Case, S.D. Alexandratos and A.A. Kriger Extraction of Cu(II) from Sulfuric Acid by Macrocycle-Synergized Cation Exchange: Comparing a Novel Impregnated Resin with its Solvent-Extraction Analog Analytical Chemistry, 65, 3389-3395 (1993).

5. A.W. Trochimczuk and S.D. Alexandratos Synthesis of Bifunctional lon Exchange Resins through the Arbusov Reaction: Effect on Selectivity and Kinetics Journal of Applied Polymer Science, in press (1994).

6. E.P. Horwitz, R. Chiarizia, H. Diamond, R.C. Gatrone, S.D. Alexandratos, A.W. Trochimczuk and D.W. Crick Uptake of Metal lons by a New Chelating lon Exchange Resin. Part 1: Acid Dependencies of Actinide lons

Solvent Extraction and lon Exchange 11, 943-966 (1993).

7. R. Chiarizia, E.P. Horwitz, R.C. Gatrone, S.D. Alexandratos, A.W. Trochimczuk and D.W. Crick

Uptake of Metal lons by a New Chelating lon Exchange Resin. Part 2: Acid

Dependencies of Transition and Post-Transition Metal lons

Solvent Extraction and lon Exchange 11, 967-985 (1993). 
ALEXANDRATOS // 13591-8

8. S.D. Alexandratos, A.W. Trochimczuk, D.W. Crick, E.P. Horwitz, R.C. Gatrone and R. Chiarizia

Synthesis of a Novel Diphosphonate-Based Ion Exchange Resin with Enhanced Metal lon Selectivity

In "Emerging Separation Technologies for Metals and Fuels", Edited by V.I. Lakshmanan, R.G. Bautista and P. Somasundaran; The Minerals, Metals \& Materials Society, 1993. pp. 111-117.

9. $\quad$ A.W. Trochimczuk, E.P. Horwitz and S.D. Alexandratos Complexing Properties of Diphonix, a New Chelating Resin with Diphosphonate Ligands, Toward Ga(III) and $\ln (I I I)$ Separation Science and Technology 29, 543-549 (1994).

10. K.L. Nash, P.G. Rickert, J.V. Muntean and S.D. Alexandratos Uptake of Metal lons by a New Chelating Ion Exchange Resin. Part 3: Protonation Constants via Potentiometric Titration and Solid State ${ }^{31} \mathrm{P}$ NMR Spectroscopy

Solvent Extraction and Ion Exchange 12, $193-209$ (1994).

11. R. Chiarizia, E.P. Horwitz and S.D. Alexandratos Uptake of Metal lons by a New Chelating lon Exchange Resin. Part 4: Kinetics Solvent Extraction and lon Exchange 12, 211-237 (1994).

12. S.D. Alexandratos

Synthesis of Tetraalkyl Vinylidene Diphosphonate Monomer U.S. Patent 5,256,808 (Oct. 26, 1993).

13. E.P. Horwitz, R. Chiarizia and S.D. Alexandratos Uptake of Metal lons by a New Chelating lon Exchange Resin.Part 5: The Effect of Matrices on Actinides

Solvent Extraction and lon Exchange, in press (1994).

14. E.P. Horwitz, S.D. Alexandratos, R.C. Gatrone and R. Chiarizia Phosphonic Acid Based lon Exchange Resins U.S Patent Pending (1994). 

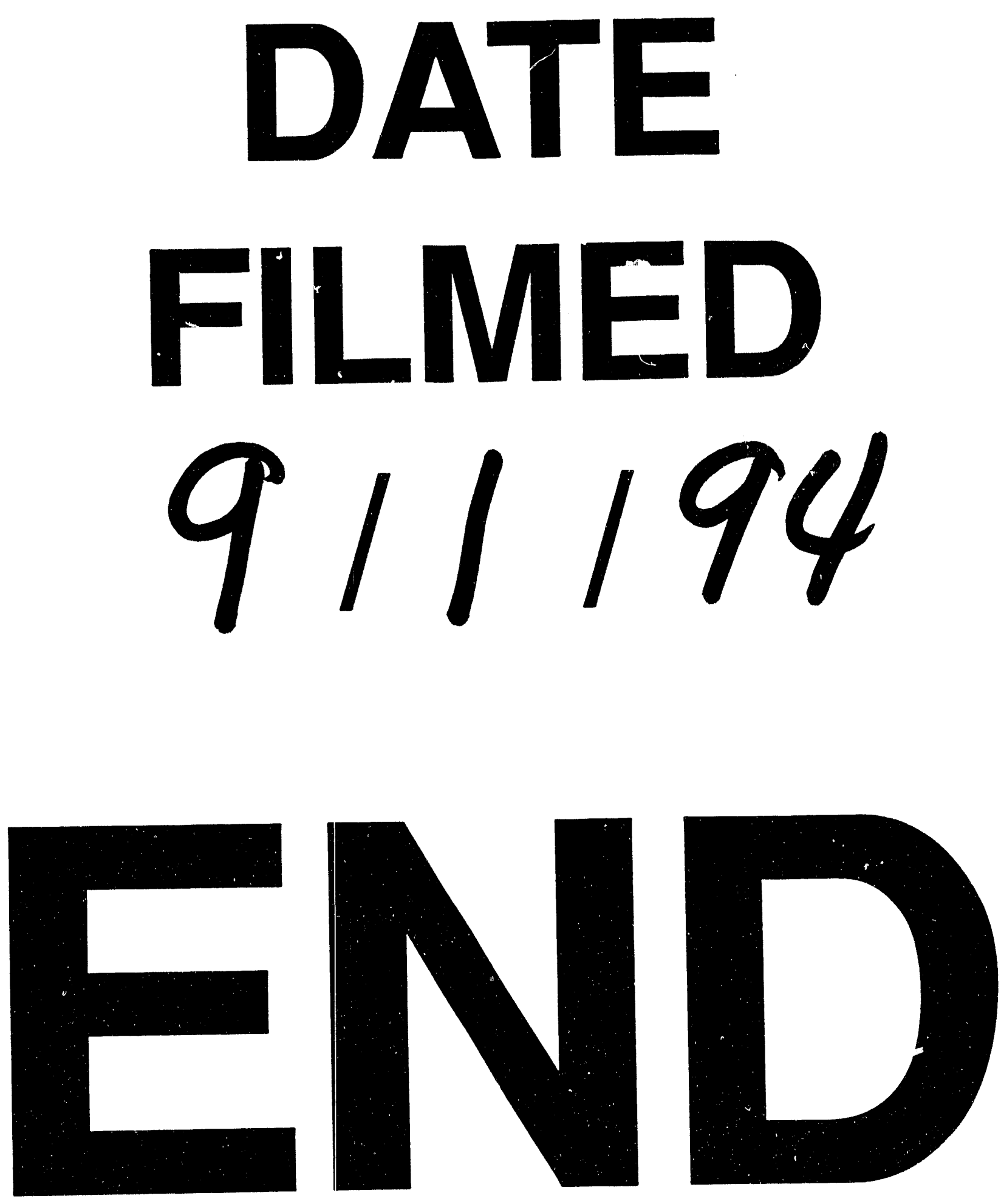
